\title{
Respiratory System Findings Completion Status
}

National Cancer Institute

\section{Source}

National Cancer Institute. Respiratory System Findings Completion Status. NCI

Thesaurus. Code 124008.

A term used to describe the state or condition of the completeness of the respiratory system findings data. 